\title{
Impact of Physical Stretching Exercise on Feto-Maternal Outcomes Among Mild Preeclamptic Pregnant Women in Egypt
}

\author{
Sahar M. Yakout \\ Department of Obstetric and Gynecological Nursing, Alexandria University, Faculty of Nursing, Alexandria, Egypt \\ Email address: \\ Ahmedmatok@yahoo.com
}

To cite this article:

Sahar M. Yakout. Impact of Physical Stretching Exercise on Feto-Maternal Outcomes Among Mild Preeclamptic Pregnant Women in Egypt. American Journal of Nursing Science. Vol. 5, No. 3, 2016, pp. 114-121. doi: 10.11648/j.ajns.20160503.16

Received: May 13, 2016; Accepted: May 26, 2016; Published: June 14, 2016

\begin{abstract}
Preeclampsia is a disorder of widespread vascular endothelial malfunction and vasospasm that occurs after 20 weeks' gestation. It accounts for $22 \%$ of maternal deaths, $18 \%$ of all pre-mature births worldwide. Recently, recommendations about exercise in pregnant women with hypertension or at risk of pre-eclampsia (PE) development have been studied with the objective of trying to reduce the deleterious effects of hypertensive disorders in pregnancy, including the reduction of the incidence of PE. This study aimed to evaluate the impact of practicing self-independent physical stretching exercise by pregnant women with mild preeclampsia on their feto - maternal outcomes. Setting: The study was conducted in antenatal as well as labor units at El-Shatby Maternity University Hospital in Alexandria a purposive sample of 64 pregnant women participated in the study. Three tools were used to collect the necessary data and apply: Structured Interviewing Questionnaire to collect data regarding mothers socio-demographic variables, an observational check list which includes information related to fetomaternal outcomes and an instruction guideline which includes the importance and different types of stretching physical exercise. Results of the current study illustrated that the mean systolic and diastolic blood pressure before and after practice of stretching physical exercise had a significant difference $(\mathrm{P}=0.001)$. The practice of stretching physical exercise during pregnancy have ranged from not practice $100 \%$ before instruction to as high as $70.3 \%$ after interventions. As regards to fetomaternal outcomes, (55.6\%) of studied subjects who practice exercise delivered vaginal and majority (89.7\%) of them who not practice exercise delivered cesarean section and the reason for C.S.; fetal distress $(52.6 \%)$. All (100\%) of the study subject who practice exercise not suffer from complications while about one half $(42.1 \%)$ who not practice exercise suffer from severe preeclampsia. physical exercise did not represent a risk of the neonatal outcomes studied: low birth weight (1500-2500 g) was $4.4 \%$, adequacy of weight $(95.6 \%)$, prematurity was $(8.9 \%)$ and no birth defect was $(89 \%)$. It was concluded that, practice of stretching physical exercise with mild preeclampsia promote mothers feto-maternal outcomes and not produce maternal or neonatal risk than who do not practice. The physical exercise was safe and it was not harmful to mother and newborn. So, it was recommended that low risk women should be adherence to physical exercise and lifestyle changes.
\end{abstract}

Keywords: Mild Preeclampsia, Physical Stretching Exercise, Fetomaternal Outcomes, Cesarean Section, Normal Delivery

\section{Introduction}

Hypertensive disorders is the most common medical complication occur during pregnancy, affecting $10 \%$ to $20 \%$ of all pregnancies worldwide, Hypertensive disorders were reported as the cause of $16.1 \%$ of maternal deaths in developed countries, $9.1 \%$ in Africa, 9.1\% in Asia, and 25.7\% in Latin America and the Caribbean. Pre-eclampsia and eclampsia complicate $2 \%-8 \%$ of pregnancies and, overall, $10 \%-15 \%$ of direct maternal deaths are associated with these conditions. [1,2].

Hypertensive disorders are one of the most common causes of death due to pregnancy. [3] They resulted in 29,000 deaths in 2013-down from 37,000 deaths in 1990. [4] In Egypt, it is the second direct causes of maternal mortality 14.9 / 100,000 live births in 2013. [5] Preeclampsia usually occurs after 32 weeks; however, if it occurs earlier it is associated with worse outcomes. Women who have had 
preeclampsia are at increased risk of heart disease and stroke later in life. [3, 6].

Preeclampsia is a disorder of widespread vascular endothelial malfunction and vasospasm that occurs after 20 weeks' gestation. It is defined as the presence of a systolic blood pressure (SBP) greater than or equal to $140 \mathrm{~mm} \mathrm{Hg}$ or a diastolic blood pressure (DBP) greater than or equal to $90 \mathrm{~mm}$ $\mathrm{Hg}$ or higher, on two occasions at least 4 hours apart in a previously normotensive patient, or an SBP greater than or equal to $160 \mathrm{~mm} \mathrm{Hg}$ or a DBP greater than or equal to $110 \mathrm{~mm}$ $\mathrm{Hg}$ or higher. In addition to the blood pressure criteria, proteinuria of greater than or equal to 0.3 grams in a 24-hour urine specimen, or a urine dipstick protein of $1+$ (if a quantitative measurement is unavailable) is required to diagnose preeclampsia. [7, 8] It accounts for $22 \%$ of maternal deaths and $18 \%$ of all pre-mature births and it increases maternal risk for future cardiovascular disease. Preceding the clinical manifestation of this disease is a period of largely asymptomatic gradual decline in health status, beginning in early pregnancy, characterized by autonomic dis-regulation, labile blood pressure, insulin resistance, and oxidative stress. So, there are numerous pathologic changes in maternal systems, though the etiology of preeclampsia remains unknown-most likely multifactorial and no preventive measures currently exist to eliminate the threat of developing this dangerous disease. Risk factors include certain genetic traits, obesity, nulliparous status, history of preeclampsia, diabetes, hypertension, and sedentary lifestyle. Unfortunately, many of these risk factors are not modifiable or are very difficult to modify, especially during pregnancy. [9] One potentially changeable risk factor is physical activity, women who engaged in moderate to vigorous leisure time physical activities (LTPAs) before and during pregnancy experienced up to a $35 \%$ reduction in preeclampsia. $[10,11,12]$.

The practice of physical exercise is recommended in a low-risk pregnancy because of its benefits to maternal health. In addition, exercise is considered a safe activity for both, mother and the fetus, especially when performed under professional guidance and supervision [13, 14]. In low-risk pregnant women, when low-intensity and moderate-intensity exercise is performed, it does not alter newborn weight [13, $15,16]$ and reduces the risk of prematurity $[17,18]$.

Recently, recommendations about exercise in pregnant women with hypertension or at risk of PE development have been studied with the objective of trying to reduce the deleterious effects of hypertensive disorders in pregnancy, including the reduction of the incidence of $\mathrm{PE}$. The mechanism involved would be that preeclamptic women through physical stretching exercise their blood pressure levels and cardiovascular fitness were improved. [19, 20, 21]. In addition, exercise may decrease maternal concentration of oxidative substances, stimulate placental growth, and act on the reversal of endothelial dysfunction [22]. In recent years, endothelial dysfunction has emerged as the leading phenomenon responsible for the clinical signs of the disorder. Factors proposed to cause endothelial dysfunction in preeclampsia include poor placental vascular remodeling and placental ischemia, oxidative stress, excessive inflammation, imbalance in angiogenic factors and the loss of endogenous protective regulators. [23, 24].

Low-intensity exercise such as yoga, prenatal stretching exercises (PSEs) have positive effects on reducing stress. Yet, few studies to date examined similar effects of PSEs, which are commonly prescribed by nurses. Previously we conducted a randomized trial comparing two exercises, stretching and walking, on the incidence of preeclampsia among sedentary pregnant women, and found that women in the daily PSE program experienced a significantly lower incidence of preeclampsia than expected. [25, 26] So, stretching exercises may be more effective at reducing the risk of preeclampsia for pregnant women who have already experienced the condition and who do not follow a workout routine. [27].

\subsection{Significance of the Study}

Physical Stretching exercise could provide protection against preeclampsia because stretchers produced more transferrin. Transferrin is a plasma protein that transports iron through the blood and protects against oxidative stress on the body. These results could help maternity nurses recommend different exercise plans based on an individual pregnant woman's needs and abilities. Following an active exercise plan is good, but only if a pregnant woman is truly able to do it. For some who already have a risk of preeclampsia, stretching might be a better option. [12].

Physiologically, the performance of physical exercise during pregnancy offers benefits. Furthermore, it is well known that physical activity has an important role in hypertensive subject. There is a lack of knowledge about whether effects of physical exercise are associated or not with a maternal or fetal risk in pregnant women with hypertensive disorders or those with risk of developing PE. The aim of the present study was to evaluate the impact of practicing self-independent physical stretching exercise by pregnant women with chronic hypertension and mild preeclampsia on feto-maternal outcomes.

\subsection{Aim of the Study}

This study aimed to evaluate the impact of practicing selfindependent physical stretching exercise by pregnant women with mild preeclampsia on their feto - maternal outcomes.

\subsection{Research Hypothesis}

Practice of self-independent physical stretching exercise by pregnant women with mild preeclampsia will promote their feto - maternal outcomes.

\subsection{Operational Definition}

Fetal outcome:

Fetus who delivered with normal or abnormal weight, APGAR score and physical assessment.

Maternal outcomes: Methods of delivery and maternal complications. 
Mild Preeclampsia: Preeclampsia's clinic diagnosis was done by attending doctors and was defined when patient had systolic blood pressure between 140-160 $\mathrm{mm} / \mathrm{Hg}$ and/or diastolic between $90-110 \mathrm{~mm} / \mathrm{Hg}$, sitting down (confirmed with 2 tests separated by 4 hours each) and proteinuria $>300$ $\mathrm{mg}$ in 24 hours urine, without concomitant urine infection. without pre-convulsive symptoms (headache, blurred vision, epigastric pain, tinnitus) or fetal compromise (IUGR or oligohydramnios).

\section{Subjects and Methods}

\subsection{Design and Setting}

Quantitative Quasi Experimental Prospective study research design. The study was conducted in antenatal as well as labor units at El-Shatby Maternity University Hospital in Alexandria, Egypt. It is an ideal setting to determine fetal and maternal outcomes.

\subsection{Subjects}

Subjects consisted of 64 mild preeclampsia pregnant women were selected at 28 weeks of gestation according to the following.

\subsubsection{Inclusion Criteria}

Pregnant women with mild preeclampsia, singleton pregnancy and Cephalic presentation.

\subsubsection{Exclusive Criteria}

Women with multiple pregnancies, cervical insufficiency, vaginal bleeding, heart disease, kidney failure, and neurologic disorders.

\subsection{Instruments of Data Collection and Application}

Data of this study was collected using the following three tools:

1. Structured Interviewing Questionnaire (SIQ) was developed by the researchers based on literature review, it included three parts:

The first part is to collect data regarding mothers sociodemographic variables such as age, level of education, job, family income, social support, type of support and practice of exercise. Part two was covered past obstetric history such as no of pregnancy, No of living children and complications during last pregnancy. Part three was covered measurement of blood pressure during follow up interval.

2. An observational check list

It includes information related to fetomaternal outcomes which include maternal complications, type of delivery, gestational age, Apgar score, reason for cesarean section, newborn condition, infant sex, birth weight, birth defect and neonatal complications.

3. An instruction guideline was developed after extensive review of literature $[28,29]$ which include the importance and different types of stretching physical exercise as following:
Warm-up, stretching back to correct the curvature, Neck stretch: This exercise helps ease tension in your neck, Chest: This heavenly stretch relieves tension in your chest and upper back, Shoulder circles: While seated or standing, rotate your shoulders backward and down in the largest circle you can make. This opens the chest, counteracting the rounded shoulders so many pregnant women get more oxygen, Abdomen; Open the front of the body with this liberating stretch, designed to elongate the muscles working so hard to support your baby belly, Hips: This classic hip opener can also help relieve discomfort related to sciatica and stretch your belly while you're at it, Legs: Swelling, cramping has been tough on your legs. Give them a much-needed break with this easy stretch, Entire Body: This stretch opens your back and chest to promote deep breathing, which alleviates stress and the physical tension that accompanies it.

\subsection{Validity and Reliability}

Tools were submitted to five academic nursing experts in the field of obstetric and gynecologic nursing to test the content validity of it. Modifications were carried out according to the academic nursing experts' judgment on clarity of sentences and the appropriateness of the content. Tool reliability was tested using Alpha Cronbach test. Its result was 0.80 which indicates an accepted reliability of the tool.

\subsection{Administrative Design}

An official permission was obtained from the concerned departments to conduct the proposed study.

\subsection{Pilot Study}

The study tools were pre-tested on a random sample of 6 women $(10 \%)$ selected from the same study setting to check the clarity, applicability, any difficulties with their application, and to determine the time needed for completion of the tools. Modification of the tools was done according to the pilot study results. Subjects who shared in the pilot study were excluded from the study subjects.

\subsection{Procedure}

The study was achieved through the following steps:

1- Before interviewing the participant, the researcher trained themselves to standardized practice stretching physical exercise for learning of women during interview.

2- Once permission was granted to proceed with the proposed study, the researchers interview the patients who fulfilled the inclusion criteria four times $\left(1 \mathrm{st}\right.$ time at $7^{\text {th }}$ month of gestation, $2^{\text {nd }}$ at $8^{\text {th }}$ month, $3^{\text {rd }}$ at $9^{\text {th }}$ month during follow up, and $4^{\text {th }}$ time were conducted after delivery) to complete the basic data using an Interviewing Assessment Sheet (tool I).

3- During the First time the basic data was completed using an Interviewing Assessment Sheet (tool I) The purpose and nature of the study were explained. The blood pressure was measured and recorded by the researcher. Information about the importance and different types of stretching physical 
exercise was explained. Different types of stretching physical were demonstrated by the researcher. The instructions given for about 30-45 minutes. Finally, mild pre-eclamptic women re-demonstrate the physical stretching exercise.

4- The patients were instructed to perform the following set of exercise four to five times per week for 3 months till the end of pregnancy. The pre-eclamptic women instructed that, whenever you feel the need to stretch Hold each stretch to a point of mild tension for about eight to 10 seconds, then release. Each time you stretch, go a little farther, as long as you are comfortable and there is no pain. Each time you release, take a breath, then exhale as you get back into the stretch.

5- Instructional guidelines (Handout contains detailed physical stretching exercise that practiced at home) were distributed after finishing. Due to lack of space, the pregnant women were instructed to perform at home and one session taken at hospital. The mother asked to stop practice if, there were Shortness of breath, palpitations, dizziness, headache, nausea, severe or sudden abdominal pain, chest pain, back pain, pain in pubic area, vaginal bleeding, and reduced fetal movements after training.

6- The mothers were followed up monthly in the outpatient Clinic for 3 months (from 28 weeks of gestation till delivery) to ensure patients compliance to independent applications of the interventions given (practice self-stretching exercise).

7- Evaluation of the effectiveness practice exercise were evaluated by fetomaternal outcomes in $4^{\text {th }}$ time.

\subsection{Ethical Consideration}

Before the beginning of the study, an informed oral consent was taken from the women after explaining the aim of the study and its phases. The participants were assured of the confidentiality of their personal information. Women were allowed to withdraw from the study at any time. The data was collected over a period of 3 months from the beginning of June to the end of August 2015.

\subsection{Statistical Analysis}

Data were fed to the computer and analyzed using IBM SPSS software package version 20. Quantitative data were described using minimum and maximum, mean and standard deviation. Comparison between before exercise, after practice regarding categorical variables was tested using Chisquare test. When more than $20 \%$ of the cells have expected count less than 5 , correction for chi-square was conducted using Monte Carlo correction. To compare between the three periods Friedman test was applied and Significance of the obtained results was judged at the $5 \%$ level.

\section{Results}

As shown in Table 1, 37.5\% of mothers their age ranged between 20-36 years. The education background of the mother as $(42.2 \%)$ of the sample mothers has a university degree and mothers with preparatory and secondary education got the same percentage $(18.8 \%)$. However, we see that $(17.2 \%)$ of the mother have literacy. When looking at the working status of the mother, we see that $(57.8 \%)$ are housewives and $(42.2 \%)$ are workers. With respect to family income, we find that $(54.7 \%)$ of the sample have family income less than 2000 pound, and $(45.3 \%)$ had more than or equal 2000 pound as income. About one half (43.8\%) of mothers have their social support from parents and (17.2\%) from the husband and (15.6\%) from others. Moreover, (9.4\%) have their social support from brothers and $(7.8 \%)$ from sons. Type of support for mothers are represented as following; (43.8\%) of mothers had an affirmation support and $(40.6 \%)$ had an affective support and only (15.6\%) had a money support. As regard to maternal smoking about one half $(42.2 \%)$ were passive smokers and all of them $(100 \%)$ not practice exercise.

Regarding Table 2, Same percentage of mothers had one pregnancy and more than 5 pregnancy as they represent $(15.6 \%)$ of the sample. Only $(18.8 \%)$ had 4 pregnancy and (34.4\%) had two pregnancy. About one third $(32.8 \%)$ had one delivery and $(26.6 \%)$ had two delivery, also $(20.3 \%)$ had more than four deliveries. Only (10.9\%) and (9.4\%) had three and four deliveries respectfully. Moreover, (37.5\%) have one living child and (23.4\%) have two living child, and (18.8\%) have six and more living children. Only $(12.5 \%)$ have three living child and (4.7\%) have four living children. (70.3\%) of the sampled mother did not have any complication during the last pregnancy and only (29.7\%) had these complications during last pregnancy as we see that only $(3.1 \%)$ have heart diseases and $(1.6 \%)$ of the sample have hypertension and (4.7\%) have diabetes and only (9.4\%) have asthma. Moreover, we see that $(10.9 \%)$ have anaemia.

Table 3, Mean systolic and diastolic blood pressure during the three months (pre-practice and post practice 8 month and 9 month) are shown in Table 3. The results showed that systolic and diastolic blood pressure in the three period had a significant difference $(\mathrm{P}=0.001)$. Fisher test showed that the difference between systolic and diastolic blood pressure before and after practice of stretching exercises $(\mathrm{P}<0.05)$ was significant.

Table 4, shown the distribution of the study subjects according to their maternal outcomes, the majority (79.6\%) of mothers delivered at gestational age more than or equal 37 weeks of gestation. according to the type of delivery (42.1\%) delivered normal and $57.9 \%$ delivered caesarean section. The reasons for C-section were repeat cesarean sections $17.1 \%$, fetal distress $6.2 \%$, Cephalo-pelvic disproportion $6.3 \%$ and failure to induce labor $6.3 \%$. Three quarters $(75 \%)$ of the study subject had no complications. There was eight patients with severe preeclampsia and eight with diabetes mellitus.

Table 5, shown fetal outcomes, most $(92.2 \%)$ of newborn was born alive and $57.8 \%$ was male gender. Regarding the neonatal morbidity, more than two thirds $(67.2 \%$ and $73.2 \%)$ delivered with no complications and birth defect respectively. About two thirds (64.1\%) of newborn their Apgar score at 1 minute more than or equal 7 and after 5 minutes $70.3 \%$ their Apgar score more than or equal 7.

There was a significant difference between the groups 
regarding mode of delivery, fetal distress and occurrence of maternal complications as shown in Table 6. Among the 37 pregnant women who had cesarean sections, had one reason. It was observed that, $55.6 \%$ of studied subjects who practice exercise delivered vaginal compared to $10.5 \%$ who not practice exercise. Majority of them $89.5 \%$ not practice exercise delivered cesarean section (C.S) compared to $44.4 \%$ delivered normal who practice. As regard, the reason for C.S., it was observed that, $58.8 \%$ not practice exercise had fetal distress. All $(100 \%)$ of the study subjects who practice exercise not suffer from complications and same percentage $(42.1 \%)$ suffer from severe preeclampsia and diabetes mellitus from who not practice exercise respectively.

Table 7, There were a significant difference in variables related to neonatal outcomes. Among the neonatal complications, most $(89 \%)$ of subjects who practice exercise not suffer from complications compare to $15.7 \%$ not practice such as respiratory aspiration syndrome was most prevalent $(52.6 \%)$, followed by preterm $(47.4 \%)$. After analysis, physical exercise did not represent a risk of the neonatal outcomes studied: low birth weight (1500-2500 g) was 4.4\%, adequacy of weight $(95.6 \%)$, and prematurity was $(8.9 \%)$ and no birth defect was $(89 \%)$. As regard to practice group, all of the neonate after 5 minutes their Apgar score more than 7 compared to non-practice women.

Table 1. Distribution of the study subjects according to socio-demographic characteristics.

\begin{tabular}{|c|c|c|}
\hline Variables & No & $\%$ \\
\hline \multicolumn{3}{|c|}{ Maternal age (years) } \\
\hline$<19$ & 18 & 28.1 \\
\hline $20-36$ & 24 & 37.5 \\
\hline$>36$ & 22 & 34.4 \\
\hline \multicolumn{3}{|c|}{ Education of Mother } \\
\hline literacy & 11 & 17.2 \\
\hline primary & 2 & 3.1 \\
\hline preparatory & 12 & 18.8 \\
\hline secondary & 12 & 18.8 \\
\hline university & 27 & 42.2 \\
\hline \multicolumn{3}{|l|}{ Job } \\
\hline House wife & 37 & 57.8 \\
\hline worker & 27 & 42.2 \\
\hline \multicolumn{3}{|c|}{ Family Income } \\
\hline$<2000$ & 35 & 54.7 \\
\hline$\geq 20000$ & 29 & 45.3 \\
\hline \multicolumn{3}{|c|}{ Social support } \\
\hline parents & 28 & 43.8 \\
\hline husband & 11 & 17.2 \\
\hline sons & 5 & 7.8 \\
\hline brothers & 6 & 9.4 \\
\hline others & 14 & 21.9 \\
\hline \multicolumn{3}{|c|}{ Type of Supports } \\
\hline affective & 26 & 40.6 \\
\hline affirmation & 28 & 43.8 \\
\hline money & 10 & 15.6 \\
\hline \multicolumn{3}{|c|}{ Maternal smoking } \\
\hline Passive & 27 & 42.2 \\
\hline Active & 4 & 6.3 \\
\hline None & 33 & 51.5 \\
\hline \multicolumn{3}{|c|}{ Practice exercise (before training) } \\
\hline Yes & 0 & 0.0 \\
\hline No & 64 & 100.0 \\
\hline
\end{tabular}

Table 2. Distribution of the study subjects according to their past obstetrical history.

\begin{tabular}{lll}
\hline Variables & Frequency & Percent \\
\hline Number of pregnancy & & \\
one & 14 & 21.9 \\
two & 11 & 17.2 \\
three & 12 & 18.8 \\
four & 7 & 10.9 \\
five & 6 & 9.4 \\
more than 5 & 14 & 21.9 \\
Number of delivery & & \\
1 & 21 & 32.8 \\
2 & 17 & 26.6 \\
3 & 7 & 10.9 \\
4 & 6 & 9.4 \\
more than 4 & 13 & 20.3 \\
Number of living children & & \\
one & 24 & 37.5 \\
two & 15 & 23.4 \\
three & 8 & 12.5 \\
four & 3 & 4.7 \\
five & 1 & 1.6 \\
6 and more & 13 & 19.4 \\
Complication during last pregnancy & & \\
Present & 19 & 29.7 \\
Not present & 45 & 70.3 \\
Types of complication & & \\
Heat disease & 2 & 1.6 \\
Hypertension & 3 & 4.7 \\
Diabetes & 6.4 \\
Asthma & 7 & 10.9 \\
Anaemia & & \\
\hline & & \\
\hline
\end{tabular}

Table 3. The distribution of the study subjects according to mean of blood pressure measurement before and after practice physical stretching exercise during pregnancy, $\mathrm{mmHg}$.

\begin{tabular}{|c|c|c|c|c|}
\hline Variable & $\begin{array}{l}\text { Pre-practice } \\
\text { (7 month) }\end{array}$ & $\begin{array}{l}8 \text { months after } \\
\text { practice }\end{array}$ & $\begin{array}{l}9 \text { months after } \\
\text { practice }\end{array}$ & \\
\hline $\begin{array}{l}\text { Systolic blood } \\
\text { pressure }\end{array}$ & $115.0 \pm 8.40$ & $99.4 \pm 10.28$ & $100.4 \pm 7.23$ & $\begin{array}{l}F=7.377 \\
P=0.001\end{array}$ \\
\hline $\begin{array}{l}\text { Diastolic } \\
\text { blood } \\
\text { pressure }\end{array}$ & $77.2 \pm 10.7$ & $72.8 \pm 6.33$ & $64.3 \pm 5.90$ & $\begin{array}{l}f=6.614 \\
P=0.002\end{array}$ \\
\hline
\end{tabular}

SD: Standard deviation, ANOVA: Analysis of variance

* systolic and diastolic hypertension, defined by the mean of three clinic readings giving an $\mathrm{SBP}>160 \mathrm{~mm} \mathrm{Hg}$ and and $\mathrm{DBP}>95 \mathrm{~mm} \mathrm{Hg}$.

Table 4. Distribution of the study subjects according to their maternal outcomes.

\begin{tabular}{lll}
\hline Outcomes & Frequency & Percent \\
\hline Gestational age & & \\
$<37$ & 14 & 21.8 \\
$\geq 37$ & 51 & 79.6 \\
Type of delivery, (\%) & & \\
Vaginal delivery & 27 & 42.1 \\
Cesarean & 37 & 57.9 \\
Reason for C-section, (\%) & & \\
Repeat C-sections & 11 & 17.1 \\
Fetal distress & 18 & 6.2 \\
Cephalo-pelvic disproportion & 4 & 6.3 \\
Failure to induce labor & 4 & 6.3 \\
Maternal complications, (\%) & & \\
No complications & 48 & 75 \\
severe PE & 8 & 12.5 \\
Diabetes mellitus & 8 & 12.5 \\
\hline
\end{tabular}


Table 5. Distribution of the study subjects according to their fetal outcomes.

\begin{tabular}{lll}
\hline Variables & Frequency & Percent \\
\hline New-born conditions & & \\
Live born & 59 & 92.2 \\
stillborn & 5 & 7.8 \\
Infant's sex & & \\
male & 37 & 57.8 \\
female & 27 & 42.2 \\
Birth Weight (grams) & & \\
$>2500$ grams & 50 & 78.1 \\
1500 - 2500 grams & 14 & 21.9 \\
Classification of weight according to gestational age & & \\
SGA & 9 & 14.1 \\
AGA & 53 & 82.8 \\
LGA & 2 & 3.1 \\
APGAR at the 1st minute & & \\
$<7$ & 23 & 35.9 \\
$\geq 7$ & 41 & 64.1 \\
APGAR at the 5th minute & & \\
$<7$ & 45 & 70.3 \\
$\geq 7$ & 19 & 29.7 \\
Birth defect & & \\
No birth defect & 47 & 73.2 \\
With congenital anomaly & 11 & 17 \\
Mortality & 5 & 7.8 \\
Neonatal complication & & \\
No complication & 43 & 67.2 \\
Preterm & 14 & 21.9 \\
Neonatal hyper bilirubinemia & 2 & 3.1 \\
Birth asphyxia & 2 & 3.1 \\
Respiratory aspiration syndrome & 3 & 4.7 \\
\hline & & \\
\hline
\end{tabular}

Table 6. Maternal outcomes in pregnant women with mild Preeclampsia PE, according to practice or not practice physical stretching exercise after intervention.

\begin{tabular}{|c|c|c|c|c|c|}
\hline \multirow[t]{2}{*}{ Outcome } & \multicolumn{2}{|c|}{$\begin{array}{l}\text { Practice } \\
(\mathrm{n}=45)\end{array}$} & \multicolumn{2}{|c|}{$\begin{array}{l}\text { Not practice } \\
(\mathrm{n}=19)\end{array}$} & \multirow[t]{2}{*}{$\mathbf{p}$} \\
\hline & No & $\%$ & No & $\%$ & \\
\hline \multicolumn{6}{|l|}{ Type of delivery } \\
\hline Vaginal delivery & 25 & 55.6 & 2 & 10.5 & \multirow{2}{*}{$0.001^{*}$} \\
\hline Cesarean & 20 & 44.4 & 17 & 89.5 & \\
\hline \multicolumn{6}{|l|}{ Reason for C-section } \\
\hline Repeat C-sections & 8 & 40 & 3 & 17.6 & ${ }^{\mathrm{FE}} \mathrm{p}=1.000$ \\
\hline Fetal distress & 8 & 40 & 10 & 58.8 & $0.005^{*}$ \\
\hline $\begin{array}{l}\text { Cephalopelvic } \\
\text { disproportion/macrosomia }\end{array}$ & 1 & 5.8 & 3 & 4.7 & ${ }^{\mathrm{FE}} \mathrm{p}=1.000$ \\
\hline Failure to induce labor & 3 & 6.7 & 1 & 5.3 & ${ }^{\mathrm{FE}} \mathrm{p}=1.000$ \\
\hline \multicolumn{6}{|l|}{ Maternal complications } \\
\hline No complications & 45 & 100.0 & 3 & 15.8 & ${ }^{\mathrm{FE}} \mathrm{p}<0.001^{*}$ \\
\hline Severe PE & 0 & 0.0 & 8 & 42.1 & ${ }^{\mathrm{FE}} \mathrm{p}<0.001^{*}$ \\
\hline Diabetes mellitus & 0 & 0.0 & 8 & 42.1 & ${ }^{\mathrm{FE}} \mathrm{p}<0.001^{*}$ \\
\hline
\end{tabular}

$\mathrm{p}$ : $\mathrm{p}$ value for chi square test for comparing between the two studied groups FE: Fisher Exact for Chi square test

*: Statistically significant at $\mathrm{p} \leq 0.05$

Table 7. Neonatal outcomes in pregnant women with mild Pre-eclampsia $(P E)$, according to practice exercise or not practice physical stretching exercise after intervention.

\begin{tabular}{llllll}
\hline Outcome & $\begin{array}{l}\text { Practice } \\
(\mathbf{n}=\mathbf{4 5})\end{array}$ & \multicolumn{3}{l}{$\begin{array}{l}\text { Not practice } \\
(\mathbf{n}=19)\end{array}$} & $\mathbf{p}$ \\
\hline Birth weight & No & $\%$ & No & $\%$ & \\
2500 & & & & & \\
$1500-2500$ & 43 & 95.6 & 7 & 36.8 & ${ }^{\mathrm{FE}} \mathrm{p}<0.001^{*}$ \\
\hline
\end{tabular}

\begin{tabular}{|c|c|c|c|c|c|}
\hline \multirow{2}{*}{$\begin{array}{l}\text { Outcome } \\
\text { Neonatal adequacy of } \\
\text { weight to gestational age }\end{array}$} & \multicolumn{2}{|c|}{$\begin{array}{l}\begin{array}{l}\text { Practice } \\
(\mathrm{n}=45)\end{array} \\
\end{array}$} & \multicolumn{2}{|c|}{$\begin{array}{l}\begin{array}{l}\text { Not practice } \\
(n=19)\end{array} \\
\end{array}$} & \multirow[t]{2}{*}{$\mathbf{p}$} \\
\hline & & & & & \\
\hline SGA & 2 & 4.4 & 7 & 36.8 & \multirow{3}{*}{${ }^{\mathrm{MC}} \mathrm{p}<0.001^{*}$} \\
\hline AGA & 43 & 95.6 & 10 & 52.6 & \\
\hline LGA & 0 & 0.0 & 2 & 10.5 & \\
\hline \multicolumn{6}{|l|}{ Gestational age at birth } \\
\hline$<37$ & 41 & 91.1 & 10 & 52.6 & \multirow{2}{*}{${ }^{\mathrm{FE}} \mathrm{p}=0.001^{*}$} \\
\hline$\geq 37$ & 4 & 8.9 & 9 & 47.4 & \\
\hline \multicolumn{6}{|l|}{ Apgar 1 minute } \\
\hline$<7$ & 38 & 84.4 & 3 & 15.8 & \multirow{2}{*}{$<0.001^{*}$} \\
\hline$\geq 7$ & 7 & 15.6 & 16 & 84.2 & \\
\hline \multicolumn{6}{|l|}{ Apgar 5 minutes } \\
\hline$<7$ & 45 & 100.0 & 0 & 0.0 & \multirow{2}{*}{$<0.001^{*}$} \\
\hline$\geq 7$ & 0 & 0.0 & 19 & 100.0 & \\
\hline \multicolumn{6}{|l|}{ Birth defect } \\
\hline No birth defect & 40 & 89.0 & 7 & 36.8 & $<0.001^{*}$ \\
\hline $\begin{array}{l}\text { With defect or congenital } \\
\text { anomaly }\end{array}$ & 2 & 4.4 & 9 & 47.4 & ${ }^{\mathrm{FE}} \mathrm{p}<0.001^{*}$ \\
\hline Mortality & 3 & 6.6 & 2 & 10.5 & ${ }^{\mathrm{FE}} \mathrm{p}=0.629$ \\
\hline \multicolumn{6}{|l|}{ Neonatal complication } \\
\hline No complication & 40 & 89.0 & 3 & 52.6 & \multirow{5}{*}{${ }^{\mathrm{MC}} \mathrm{p}<0.001^{*}$} \\
\hline Preterm & 5 & 11.0 & 9 & 47.4 & \\
\hline $\begin{array}{l}\text { Neonatalhyper } \\
\text { bilirubinemia }\end{array}$ & 0 & 0.0 & 2 & 10.5 & \\
\hline Birth asphyxia & 0 & 0.0 & 2 & 10.5 & \\
\hline $\begin{array}{l}\text { Respiratory aspiration } \\
\text { syndrome }\end{array}$ & 0 & 0.0 & 3 & 52.6 & \\
\hline
\end{tabular}

$\mathrm{p}$ : $\mathrm{p}$ value for chi square test for comparing between the two studied groups MC: Monte Carlo for Chi square test

FE: Fisher Exact for Chi square test *: Statistically significant at $\mathrm{p} \leq 0.05$

\section{Discussion}

The results of this study showed that pregnant women that, practice stretching physical exercise with an a mild preeclampsia and chronic hypertension did not increase risk of maternal and neonatal outcomes and especially did not represent risk of hypertensive complications, prematurity, low fetal weight, or C-section rates.

Because of higher adherence (70.3\%) of the participants in practice physical stretching exercise may have benefited more than the not practice $(29.7 \%)$. This condition, added to the fact that most pregnant women previously led a sedentary lifestyle, could explain the great amount of women refusing to participate in the study and lower adherence to practice stretching exercise as Yeo S, 2009, [12]. who stated that many women had difficulty in meeting the demands and proposals of the exercise program, discontinuing after some sessions, missing many sessions, and showing a low protocol adherence.

The difference between systolic and diastolic blood pressure before and after practice of stretching exercises was significant. Because oxidative stress has been associated with the development of preeclampsia as Rogers et al., 2006 reported and findings from other study has suggested a possible decrease in oxidative stress with yoga which contains stretching [30, 31].

Regarding maternal outcomes, about one half $(42.1 \%)$ of the study subjects not practice stretching exercise develop severe PE, these results is incongruence with the findings by Yeo et al. [26] who studied pregnant women with a previous 
history of PE and also found no difference in PE development between those engaged in walking and those performing stretching exercises, five times a week during pregnancy.

High cesarean section rates were observed in women who not practice stretching exercise (89.7\%). Furthermore the high rates of cesarean section found in this study could be related to the obesity, fetal distress or repeated cesarean section. It is well known that obesity is an important risk factor for operative delivery [32]. In a meta-analysis including 33 studies, overweight, obese, and morbidly obese pregnant women had a twofold to threefold increased risk of cesarean section, when compared to pregnant women of normal weight [33].

After analysis, physical exercise did not represent a risk of the neonatal outcomes a minority had low birth weight, and prematurity most of them had adequacy of weight and prematurity and the majority had no birth defect was. As regard to practice group, all of the neonate after 5 minutes their apgar score more than 7 compared to nonpractice women. The presented study supported by Yeo Set 2008, who stated that a prematurity rate of $22 \%$ among pregnant women who walked compared to $11 \%$ who only performed stretching exercises [26].

Majority of the study subject practice exercise after health education and training, this may be because stretching exercise not has requirements that each exercise type imposes. this result supported by Clapp et al. [34] who observed an increase in the velocity of placental growth and improvement in placental function which could be attributed to favorable physiological alterations due to physical exercise, such as an increase in maternal blood circulation.

In contrast, women performing high-intensity physical activity during pregnancy may have more low-weight and small-for-gestational-age (SGA) newborns at birth [35, 36]. But in the present study, there was difference in adequacy of weight to gestational age, as well as in Apgar scores, between women who practice stretching exercise or not practice, probably because exercise was of low intensity and controlled, therefore considered safe for fetal vitality.

In a recent systematic review of randomized controlled trial, case control and cohort studies regarding exercise and physical activity in the prevention of worsening preeclampsia performed by health pregnant women showed a possible protective effect of leisure time physical activity in the worsening of preeclampsia [37].

It is important that midwives and nurses to have clearer guidance on self-independent physical stretching exercise which can be used to enhance and sustain physical activity throughout pregnancy. It is possible that women can become or stay physically active throughout their pregnancy. These interventions are most effective when delivered face-to-face. Training for midwives and nurses in practice and implementation could enhance delivery of health messages and intervention at routine patient appointments. This research article provides new knowledge about the benefits practice physical stretching exercise for increasing physical activity throughout pregnancy. It is important for those health professionals who are involved in the provision of antenatal education and public health messages.

\section{Conclusions and Recommendation}

\subsection{Conclusion}

Practice physical stretching exercise in pregnant women with chronic hypertension and mild preeclampsia, performed three to five a week, regarding the practice of stretching physical exercise during pregnancy have ranged from not practice $100 \%$ to as high as $70.3 \%$. The large range is due to the compliance to instructional guideline that have been used in this study and the conviction of mothers about the importance of practice stretching exercise in order to promote their pregnancy outcomes. Also, practice stretching physical exercise did not produce maternal and neonatal risk. The physical exercise was safe and it was not harmful to mother and newborn.

\subsection{Recommendation}

In future studies, it may be relevant to evaluate adherence to physical exercise and lifestyle changes. Also, should incorporate previous and future findings of improved pregnancy outcomes with specific volumes of physical activity. Additionally, further research is warranted to identify positive pregnancy outcomes associated with clearly identified definitions of physical activity and/or exercise.

\section{References}

[1] Ray J, Diamond P., Singh G. Bell CM. Brief overview of maternal triglycerides as a risk factor for preeclampsia. $\mathrm{Br} \mathrm{J}$ Obstet Gynaecol. 2006; 113: 379-386.

[2] WHO recommendations for prevention and treatment of preeclampsia and eclampsia. 2011. ISBN 978-92-4-154833-5.

[3] Arulkumaran, N.; Lightstone, L. (December 2013). "Severe pre-eclampsia and hypertensive crises". Best Practice \& Research Clinical Obstetrics \& Gynaecology 27 (6): 877-884.

[4] GBD 2013 Mortality and Causes of Death, Collaborators (17 December 2014). "Global, regional, and national age-sex specific all-cause and cause-specific mortality for 240 causes of death, 1990-2013: a systematic analysis for the Global Burden of Disease Study 2013". Lancet 385: 117-71.

[5] Statistics by country http://www.rightdiagnosis.com/ p/preeclampsia/ stats-country.htm (03-12-2013).

[6] Steegers E, Dadelszen P, Duvekot, J, Pijnenborg R. "Preeclampsia". The Lancet (August 2010). 376 (9741): 631-644.

[7] American College of Obstetricians and Gynecologists, Task Force on Hypertension in Pregnancy. Hypertension in pregnancy. Report of the American College of Obstetricians and Gynecologists' Task Force on Hypertension in Pregnancy. Obstet Gynecol. 2013 Nov. 122 (5): 1122-31.

[8] American College of Obstetricians and Gynecologists. Hypertension in pregnancy. ACOG Technical Bulletin No. 219. Washington DC: 1996. 
[9] Yeo S. Prenatal Stretching Exercise and Autonomic Responses: Preliminary Data and a Model for Reducing Preeclampsia, J Nurs Scholarsh. 2010 Jun 1; 42 (2): 113-121.

[10] Rousham EK, Clarke PE, Gross H. Significant changes in physical activity among pregnant women in the UK as assessed by accelerometry and self-reported activity. European Journal of Clinical Nutrition. 2006; 60: 393-400.

[11] Domingues MR, Barros AJ. Leisure-time physical activity during pregnancy in the 2004 Pelotas Birth Cohort Study. Revista de Saúde Pública. 2007; 41: 173-180.

[12] Yeo S. Adherence to walking or stretching, and risk of preeclampsia in sedentary pregnant women. Research in Nursing \& Health. 2009; 32: 379-390.

[13] Carnethon MR, Craft LL. Autonomic regulation of the association between exercise and diabetes. Exercise and Sport Sciences Reviews. 2008; 36: 12-18.

[14] Cohen J. Statistical power analysis for the behavioral sciences. 2nd ed Erlbaum; Hillsdale, NJ: 1988.

[15] Cox KL, Burke V, Gorely TJ, Beilin LJ, Puddey IB. Controlled comparison of retention and adherence in home- vs center-initiated exercise interventions in women ages 40-65 years: The S. W. E. A. T. Study (Sedentary Women Exercise Adherence Trial) Preventive Medicine. 2003; 36: 17-29.

[16] Evenson KR, Savitz DA, Huston SL. Leisure-time physical activity among pregnant women in the US. Paediatric \& Perinatal Epidemiology. 2004; 18: 400-407.

[17] Fagard RH. Effects of exercise, diet and their combination on blood pressure. Journal of Human Hypertension. 2005; 19 (Suppl.): S20-S24.

[18] Felton GM, Tudor-Locke C, Burkett L. Reliability of pedometer-determined free-living physical activity data in college women. Research Quarterly for Exercise \& Sport. 2006; 77: 304-308.

[19] Gavard JA, Artal R. Effect of exercise on pregnancy outcome. Clinical Obstetrics and Gynecology. 2008; 51: 467-480.

[20] Hinton PS, Olson CM. Predictors of pregnancy-associated change in physical activity in a rural white population. Maternal and Child Health Journal. 2001; 5: 7-14.

[21] Institute of Medicine. Food and Nutrition Board, Committee on Nutritional Status During Pregnancy, Part I: Nutritional status and weight gain. National Academy Press; Washington, DC: 1990 .

[22] Kiel DW, Dodson EA, Artal R, Boehmer TK, Lee TL. Gestational weight gain and pregnancy outcomes in obese women. Obstetrics \& Gynecology. 2007; 110: 752-758.

[23] Ahmed, A. (2011) New insights into the etiology of preeclampsia: identification of key elusive factors for the vascular complications. Thromb. Res. 127 (Suppl. 3), S72S75.

[24] Bivalacqua, T. J., Usta, M. F., Champion, H. C., Kadowitz, P.
J. and Hellstrom, W. J. Endothelial dysfunction in erectile dysfunction: role of the endothelium in erectile physiology and disease. J. Androl. (2003) 24, S17-S37.

[25] Jallo N., Bourguignon C., Taylor AG, Utz SW. Stress management during pregnancy: Designing and evaluating a mind-body intervention. Family \& Community Health. 2008; 31: 190-203.

[26] Yeo S, Davidge ST, Ronis DL, Antonakos CL, Hayashi R, O'Leary S. A comparison of walking versus stretching exercise to reduce the incidence of preeclampsia: A randomized clinical trial. Hypertension in Pregnancy. 2008; 27 (2): $113-130$

[27] Yeo S. A randomized comparative trial of the efficacy and safety of exercise during pregnancy: design and methods. Contemp Clin Trials. 2006 Dec; 27 (6): 531-40.

[28] Bob Anderson, Jean Anderson, Shelter Publications, Inc., 2002 Stretching in the Office detailed instruction on how to do each stretch 18-38.

[29] Noble E. Essential Exercises for the Childbearing Years. Boston, Houghton Mifflin, 1995.

[30] Bhattacharya S, Paney US, Verma NS. Improvement in oxidative status with yogic breathing in young healthy males. Indian Journal of Physiology and Pharmacology. 2002; 46: 349-354.

[31] Rogers MS, Wang CC, Tam WH, Li CY, Chu KO, Chu CY. Oxidative stress in midpregnancy as a predictor of gestational hyptertension and pre-eclampsia. British Journal of Obstetrics and Gynecology. 2006; 113: 1053-1059.

[32] Seligman LC, Duncan BB, Branchtein L, Miranda Gaio DS, Mengue SS, Schmidt MI. Obesity and gestational weight gain: cesarean delivery and labor complications. Revista de Saude Publica. 2006; 40 (3): 457-465.

[33] Chu SY, Kim SY, Schmid CH, et al. Maternal obesity and risk of cesarean delivery: a meta-analysis. Obesity Reviews. 2007; 8 (5): 385-394.

[34] Clapp JF, III, Kim H, Burciu B, Lopez B. Beginning regular exercise in early pregnancy: effect on fetoplacental growth The American Journal of Obstetrics and Gynecology. 2000; 183 (6): 1484-1488.

[35] Magann EF, Evans SF, Weitz B, Newnham J. Antepartum, intrapartum, and neonatal significance of exercise on healthy low-risk pregnant working women. Obstetrics and Gynecology. 2002; 99 (3): 466-472.

[36] Croteau A, Marcoux S, Brisson C. Work activity in pregnancy, preventive measures, and the risk of delivering a small-forgestational-age infant. The American Journal of Public Health. 2006; 96 (5): 846-855.

[37] Kasawara KT, Nascimento SL, Costa ML, Surita FG, Pinto e Silva JL. Exercise and physical activity in the prevention of pre-eclampsia: systematic review. Acta Obstetricia et Gynecologica Scandinavica. 2012; 91: 1147-1157. 